\title{
Upward Fire Spread: Key Flammability Properties, Similarity Solutions and Flammability Indices
}

\section{A. DELICHATSIOS}

Factory Mutual Research Corporation

Norwood, Massachusetts 02062, USA

\section{K. SAITO}

University of Kentucky

Lexington, Kentucky 40506, USA

\section{ABSTRACT}

Measurement methods and their interpretation are discussed for determining key flammability properties of charring and non-charring materials that are required as an input to a comprehensive Upward Flame Spread and Growth computer model. In addition, desirable similarity situations for upward flame spread are outlined which provide simple analytic solutions for upward flame spread rates. These solutions can be used to provide insignt and illustrate how the material properties affect upward flame spread. Among other material parameters (critical heat flux, ignition parameter, $x_{R}, x_{A}$ ), an important parameter is the material flammability number, $\operatorname{MFN}=\left(x_{R}^{+} x_{C}\right)$. $\Delta H_{\mathrm{C}} / \Delta H_{\mathrm{V}}$, ( $\mathrm{x}_{\mathrm{R}}$ radiant fraction and $x_{C}$ convective fraction of the heat release rate applied back to the surface, $\Delta \mathrm{H}_{\mathrm{c}}=$ heat of combustion, $\Delta \mathrm{H}_{\mathrm{v}}=$ effective heat of gasification), which affects inonotonically the ratio of flame height to pyrolysis length. For low values of this parameter (so that $Z_{f} / Z_{p} \leqslant 1$ ), self-sustained flame spread will even stop (except if the material is heated uniformly throughout up to the pyrolysis temperature by an external heat flux).

KEY WORDS: Flame Spread, Flammability.

\section{INTRODUCTION}

Upward fire spread is a critical phenomenon for the fire hazard behavior of materials. [1] Upward fire spread rates depend on several interacting phenomena (see e.g. Figure 1) so that prediction of such rates in different scales is difficult. Moreover, relative classification of the upward fire spread rates by using small-scale tests is dubious.

We have developed recently an Upward Fire Spread and Growth (UFSG) simulation [1] which is being used to predict and investigate upward flame spread rates on vertical walls including scale effects. This code has been designed to use as input [1] key flammability properties for a given material measured in existing flammability apparatus. Which are these flammability properties and how they can be determined both for charring and noncharring materials, is discussed in Section II. Special emphasis is given to the transient pyrolysis of materials. 


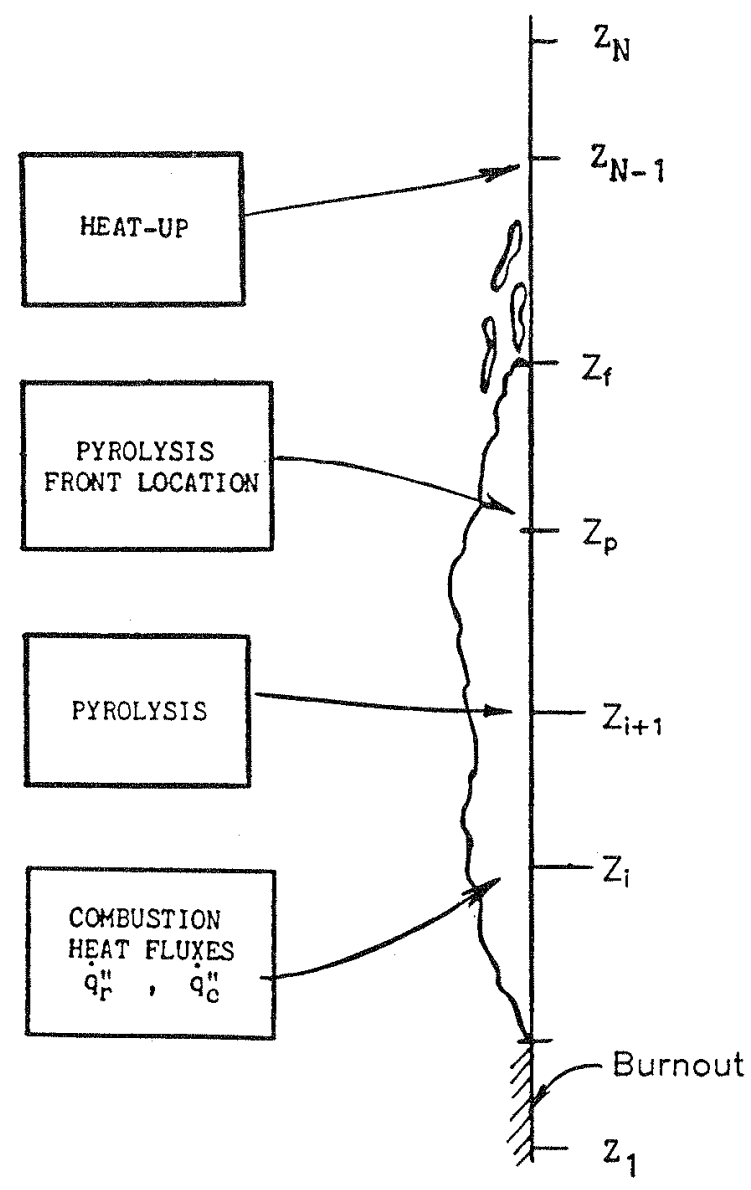

Figure 1. Physical Components of the Upward Fire Spread and Growth Simulation 
People also desire, however, simple relationships for upward flame spread rates so that they could obtain a relative (although not general) classification of materials. Such simple expressions exist for similarity situations for upward flame spread which are briefly discussed in Section III. A new similarity solution has been found which represents upward turbulent flame spread over large-scale walls. This situation could allow the determination on a sound basis of the parameters which affect largescale (radiation dominated) upward flame spread.

\section{KEY MATERIAL FLAMMABILITY PROPERTIES}

Table 1 lists the key material flamability properties required for predicting upward flame spread for charring and non-charring materials. These properties are needed for calculating all the components of upward flame spread as shown in Fig. 1, which are implemented in a new Upward Fire Spread and Growth (UFSG) code. [1] Our approach has been to keep the pyrolysis physics as simple as possible, yet retain the essential features governing transient pyrolysis phenomena which significantly affect upward flame spread rates. [1] In consistency with this approach, we model the material thermal response by using a thermal pyrolysis model, i.e. pyrolysis starts when the surface temperature reaches a pyrolysis temperature $\left(T_{S}=T_{0}\right)$ and proceeds at a rate determined by a latent heat of gasification ( $L$ ) and the heat lost into the solid. For some materials all the solid material transforms to gases, non-charring materials, while for others the solid material transforms to gases and an insulating char matrix, charring materials. The same key flammability properties together with models are planned to be used for explaining the material flammability evaluation from various National tests (Great Britain, France, USA, Germany) so that all these tests could be replaced by a more rational and comprehensive methodology for material fire hazard classification.

We discuss next how the material properties can be, or could be, determined from measurements in existing flammability apparatuses.

Heat-up and Time to Ignition (see Table 1)

From preignition data, one can obtain the thermal properties of the virgin material for both charring and noncharring materials. Such data may include $[3,4,5]$ a) piloted ignition times at various fixed heat fluxes, b) surface temperature histories, and c) mass loss histories. We have recently demonstrated $[3,4]$ how to obtain the thermal inertia of the virgin material $(\mathrm{k} \rho \mathrm{c})$ and its pyrolysis temperature $\left(\mathrm{T}_{\mathrm{p}}\right)$ from time to ignition data. Figure 2 summarizes the methodology and the necessary test conditions which are described in detail elsewhere $[3,4]$. For a thermaliy thick material covered with $50 \mu \mathrm{m}$ carbon black, one can obtain the thermal inertia (kpc), the critlcal heat flux and the pyrolysis temperature, $\mathrm{T}$, as shown in Figure 2 by plotting $1 / \sqrt{t}$ vs $\dot{q}^{\prime \prime}$. Other important and practical considerations for test evaluatiofn (finite thickness, in-depth absorption surface reflectivity) can be addressed appropriately in a simple way by an extension of the present test methodology and analysis.

\section{Transient Pyrolysis Data}

We have run an extensive experimental program [5] for characterizing the material flammability properties for transient pyrolysis both for non-charring and charring materials. A horizontal sample of a material $(12.5 \mathrm{~cm}$ diameter) was exposed in an inert $\mathbb{N}_{2}$ atmosphere to various uniform heat 
TABLE 1. KEY FLAMMABILITY PROPERTIES

\section{NON-CHARRINO}

$k, \rho, c_{p}$

$T_{p}$

$\Delta H_{v}, \mathrm{O}$

$\Delta H_{v}=L+C_{p}\left(T_{p}-T_{o}\right)$
CHARRING

Heat-up and Innition

$$
k_{v}, o_{v}, c_{p, v}
$$

$T_{p}$

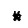

$\frac{\text { Pyrolysis Transient }}{L_{1} \rho_{v}, C_{D, v}, \rho_{c}}$

$d_{c}=\frac{k_{c}\left(T_{p}\right) T_{p}}{40 T_{p}^{4}}=\frac{k_{c} T_{p}}{4 \dot{q}_{c r}^{\prime \prime}}$

(char conductance depth)

Gaseous Combustion

$\begin{array}{lc}X_{A} & x_{A} \\ \Delta H_{c} & \Delta H_{C} \\ X_{R} & x_{R} \\ \left(T_{f}, S\right) & \left(T_{f}, S\right) \\ \text { Notes: } & \\ \text { a) Subscript } v=\text { virgin fuel, } c=c h a r \text { layer } \\ \text { b) Critical heat Flux }=o\left(T_{p}^{4}-q_{o}^{4}\right)=\dot{q}_{c r}^{*}\end{array}$

\section{METHOD OE MEASUREMENT}

1. Time to Ignition

$[2,4,5]$

2. Surface Temperature Histories [3]

3. Weight Loss

Weight Loss Histories

\section{Surface Temperature} Histories

\section{Collecting Hood Gas} Analysis

Smoke Point

* Cother effects such as reflectivity, in-depth radiation absorption are not curicntiy evaluated (see text)).

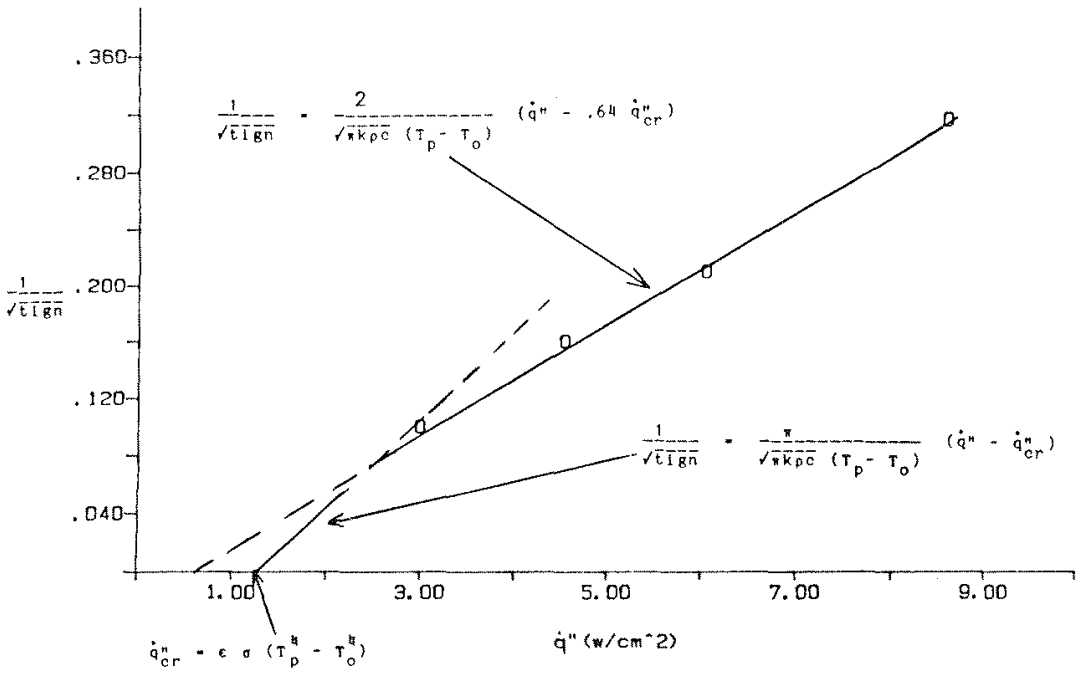

Figure 2. A proper way for plotting time to ignition data for obtaining the thermal inertia $(\mathrm{k} \rho \mathrm{c})$ and the pyrolysis temperature $\left(\mathrm{T}_{p}\right)$ as shown from the line through the experimental points. (PMMA sample is covered with 2 mil carbon black.) 
Pluxes varying from $2 \mathrm{~W} / \mathrm{cm}^{2}$ to $15 \mathrm{~W} / \mathrm{cm}^{2}$. Its surface temperature and its weight loss history for each heat flux were measured. $[2,5]$

Figures 3 and 4 for the weight loss histories clearly show how one can distinguish whether a material behaves like a "non-charring" (Figure 3) or a "charring" material (Fig. 4).

Another difference between noncharring and charring material concerns the variation of surface temperature with time after pyrolysis starts. For noncharring materials, the surface temperature after pyrolysis starts is constant [5] (e.g. about 640K for PMMA nearly independent of the heat flux). For charring materials, the surface temperature increases with time so that the reradiation losses increase significantly. These reradiation losses control the pyrolysis process in charring materials to the extent that the effects of the thermal capacity of the char are negligible and the char layer effects are characterized and influenced by the char conductivity. These results were derinitely demonstrated in recent work, after the completion of the original work in this paper [6]. These results show that the surface temperature for charring materials should be plotted, as shown in Eigure 5. Such a plot together with a mathematical model can be used to obtain the char conductivity [6] (see Table 1) or the conductance depth $d_{c}$ as shown in Table 1. By using the mass loss measurement (see Figure 4 ) one can then determine the heat of gasification L. (For noncharring fuels the heat of gasification can be determined from Figure 3.)

Our recent work [6] confirmed our approximate solution for large times after pyrolysis, which also agrees with experimental results [6]:

$$
\dot{m}^{\prime \prime}=\frac{A}{\left(\frac{t-t_{p}}{t_{p}}\right)^{1 / 2}} \text { fon } t>2 t_{p}
$$

where

$$
\begin{aligned}
& A=\frac{1}{2} \frac{\dot{q}^{\prime \prime}-\sigma T_{p}^{4}}{\Delta H_{v}}\left(\frac{(1+\lambda) d_{c}}{\delta_{v}}\right)^{1 / 2} \\
& \lambda=\frac{\Delta H_{v}}{C_{p}\left(T_{p}-T_{0}\right)} \\
& \delta_{v}=\frac{K_{v}\left(T_{p}-T_{o}\right)}{q^{\prime \prime}-\sigma T_{p}^{4}} \\
& d_{c}=\frac{K_{c} T_{p}}{4 \dot{q}^{\prime \prime}}
\end{aligned}
$$

$t_{p}=$ pyrolysis time $=\pi / 4 \frac{k \rho c\left(T_{p}-T_{0}\right)^{2}}{\left(\dot{q}^{\prime \prime}-.64 \sigma T_{p}^{4}\right)}$

Equation (1) has proven useful in the evaluation of fire spread and growth over charring materials, as it will be presented elsewhere. 


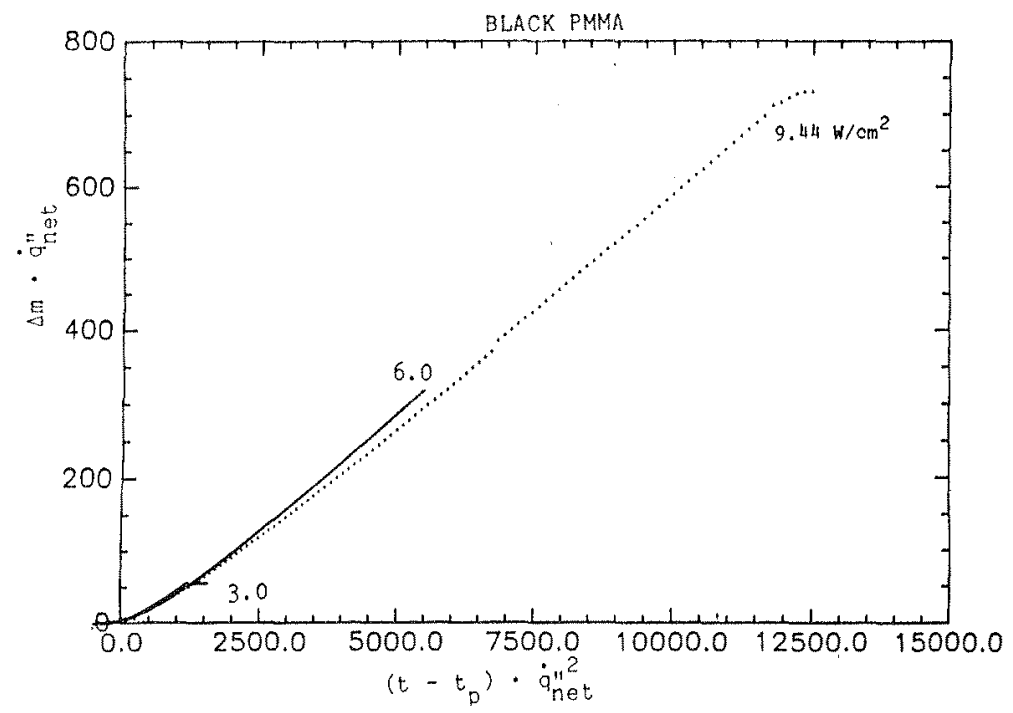

Figure 3. A plot of transient pyrolysis data for non-charring materials which allows the collapse of time history data for varlous constant heat fluxes $\left(t_{p}\right.$ is the time to pyrglysis, quet is the net heat $f l u x=\dot{q}_{e}^{\prime \prime}-\sigma_{p}^{\prime \prime}$ ) ( $\Delta \mathrm{m}$ in $\mathrm{g}, \mathrm{t}$ in $\mathrm{s}$, $\mathrm{q}_{\text {net }}^{\prime \prime}$ in $\mathrm{W} / \mathrm{cm}^{2}$ ).

\section{CELLULOSE}

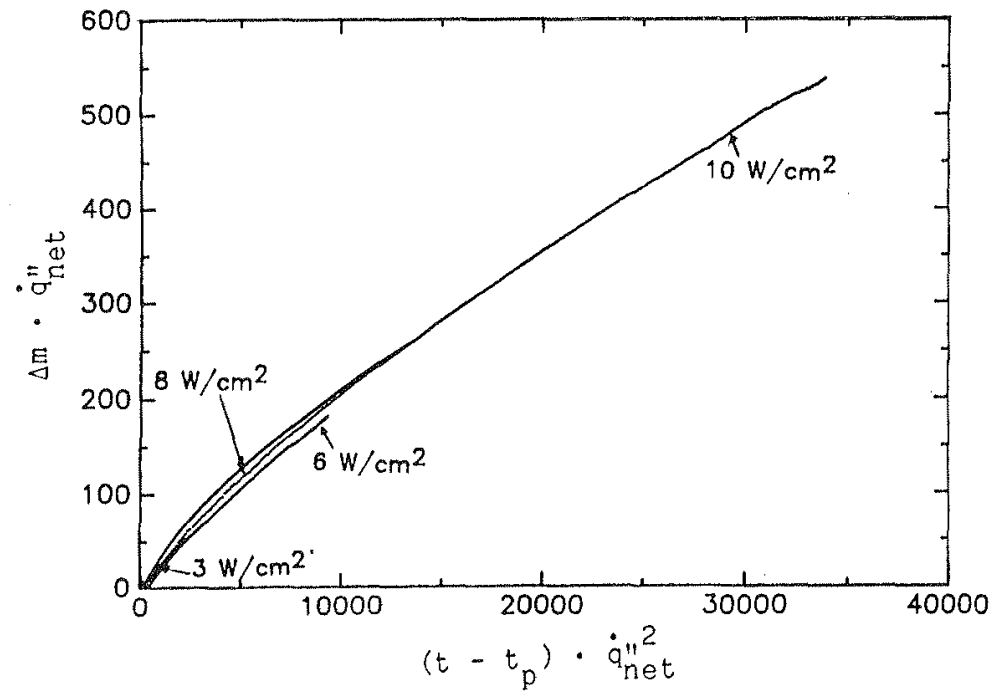

Eigure 4. Transient pyrolysis data for a charring material (cellulose made in our laboratory). Same coordinates as in Fig. 4 are used. One shouid notige the difference in behavior from Fig. $4\left(\Delta \mathrm{m}\right.$ in $\mathrm{g}, t$ in $s$, $\dot{q}_{\text {net }}^{\prime \prime}$ in $\left.\mathrm{W} / \mathrm{cm}^{2}\right)$. 


\section{CELLULOSE}

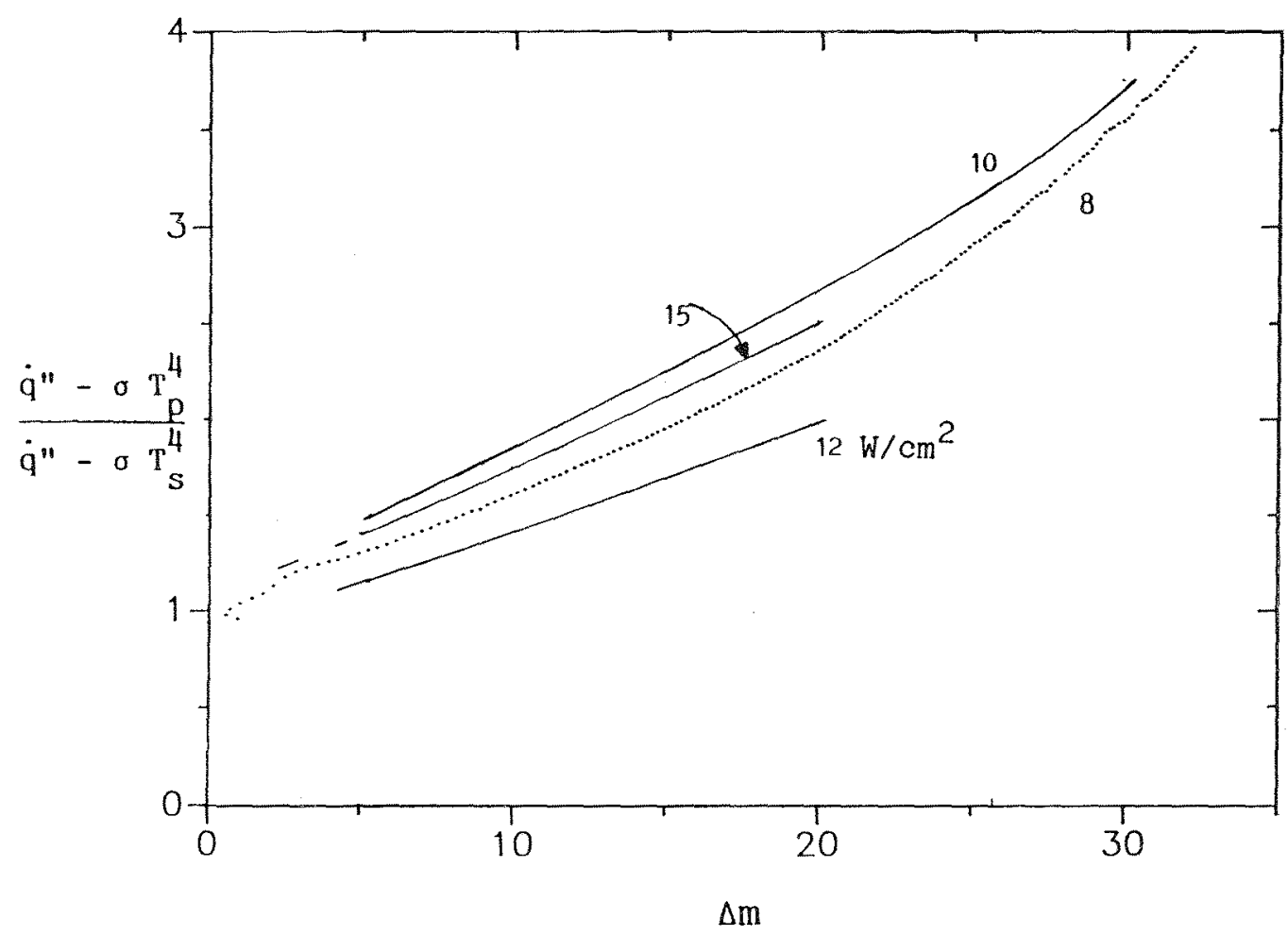

Figure 5. Surface temperature of a charring material plotted vs its weight loss measured at the same tine as the temperature. (Here $\mathrm{q}^{\prime \prime}$ is the imposed heat flux in $\mathrm{kW} / \mathrm{m}^{2}, \mathrm{~T}_{\mathrm{s}}$ is the surface temperature in $\mathrm{K}$, and $\mathrm{T}_{\mathrm{p}}$ is the pyrolysis temperature while $\Delta \mathrm{m}$ is the mass loss in $\mathrm{g}$. 
The heat of combustion $\left(\Delta H_{C}\right)$ and the effectiveness of combustion $\left(x_{A}\right)$ are required to determine the flame height and the distribution of the heat flux to the wall. [1] The radiant fraction $\left(x_{R}\right)$ and the flame temperature and stoichiometric ratio $\left(\mathrm{T}_{\mathrm{f}}, \mathrm{S}\right)$ are needed to calculate the magnitude of the radiative and the convective heat flux to the wall. [1] Such properties (including $x_{R}$ ) are being measured in existing flammability apparatus by gas analysis. $[3,7]$ The applicability of these experimental results to wall fires has not been completely assessed.

One needs to make the following comments: 1) the effects of mass transfer number, especially for charring materials, on the chemistry (e.g. smoke yield) have to be evaluated by running experiments at low heat flux levels (we estimate that these effects are negligible if $\dot{\mathrm{m}}^{\prime \prime}>8 \mathrm{~g} / \mathrm{m}^{2} \mathrm{~s}$ ); 2) the importance of the laminar smoke-point height for estimating flame radiation and smoke yield for solid (even PVC type) fuels has to be established. For this purpose a laminar smoke-point apparatus for solid materials has been developed and currently evaluated at FMRC.

\section{SIMILARITY SITUATIONS AND FLAMMABILITY INDICES}

The material pyrolysis properties in Table 1 are sufficient inputs in a new upward fire spread and growth (UFSG) code. [1] This code has already been used to predict upward fire spread on non-charring materials whose properties can be deduced from standard test measurements as demonstrated in Section 2.1 and 2.2 (see also Figs. 2, 3 and 4). An important results from this application of the code [8] is that transient pyrolysis for non-charring materials (see the initial part of the curves in Fig. 3) significantly affects the fire spread rate. The magnitude of transient pyrolysis effect [8] depends on the ratio $L / C_{p}\left(T_{p}-T_{O}\right)$.

Application of the UFSG code [1] to turbulent upward flame spread experimental data [12] on PMMA has led us recently to significant results and insight. In this situation (see Eigure 1), the heat flux (radiative and convective) to the surface over the extent of the flame has been measured to be constant [13] over a pyrolysis length of about $1.5 \mathrm{~m}\left(\mathrm{q}^{\prime \prime} \tilde{\Xi} 30 \mathrm{~kW} / \mathrm{m}^{2}\right)$. Numerical results and comparison with experiments have shown (after considerable hindsight) that the pyrolys is location, $z_{p}$, is correlated as (these results will be presented in detail elsewhere):

$$
\frac{z_{p}}{l}=\operatorname{fon}\left(\frac{t}{t_{p}}, \frac{z_{p_{o}}}{\ell}\right)
$$

The functional relationship in eq. ( $4 a$ ) is too complicated to be presented in this paper. Here $z_{p}$ is the initially pyrolyzing region, where $t_{p}$ is a pyrolysis time (see eq. $93 \mathrm{c}$ )) and $\ell$ is a characteristic length scale related to the combustion process:

$$
\ell \sim\left[\dot{\mathrm{q}}^{\prime \prime}\left(\frac{\Delta \mathrm{H}_{\mathrm{c}}}{\Delta \mathrm{H}_{\mathrm{v}}}\right)\right]^{2}
$$

(The proportionality constant accounts for the proper dimensions, it involves gravitational acceleration and ambient air properties.) This length can be derived from the flame height relationship [13]: 
$\mathrm{z}_{\mathrm{f}} \sim \dot{\mathrm{Q}}^{\prime 2 / 3} \sim\left[\dot{\mathrm{q}}^{\prime \prime} \frac{\Delta \mathrm{H}_{\mathrm{c}}}{\Delta \mathrm{H}_{\mathrm{v}}} \mathrm{z}_{\mathrm{p}}\right]^{2}$

if one sets $z_{f}=z_{p}=l$ in this equation.

Another case concerns the flame spread on large-scale wall fires $\left(z_{p}\right)$ $3 \mathrm{~m})$. In this case the heat feedback to the surface is expected to be a constant radiative fraction of the heat release rate [9] so that:

$\dot{q}^{\prime \prime} \sim x_{R} \frac{\dot{Q}^{\prime}}{Z_{f}}$

(but a maximum value of $\dot{q}^{\prime \prime}<60 \mathrm{~kW} / \mathrm{m}^{2}$ must be imposed as the flame becomes optically thick). In this case there is no characteristic length scale and one can derive by using eq. (4c) (both equalities) that:

$$
\frac{z_{f}}{z_{p}} \sim x_{R} \frac{\Delta H_{c}}{\Delta H_{v}}
$$

A similarity solution (for noncharring materials) exists for this situation but it will be presented elsewhere. (For clarification a similarity solution exists if the flame spread rate can be expressed as $t_{p} / z_{p} d z_{p} / d t=f o n$ $\left(z_{f} / z_{p}\right)$ wherein $t_{p}$ is a characteristic pyrolysis time.

The present experimental and analytical results (eq. (4a), (4b), (4c)) confirm the importance of the parameter

$\dot{q}^{\prime \prime} \frac{\Delta H_{c}}{\Delta H_{v}}$

or equivalently $\quad x_{R} \quad \frac{\Delta H_{c}}{\Delta H_{v}}=M F N$

the so-called material flamability parameter number, on flame spread processes. The time to pyrolysis, $t_{p}$, is the other important parameter (see eq. (4a)).

The same methodology (i.e. using the UFSG [8]) is being extended to charring materials; these results, however, will be presented elsewhere, together with burnout effects and comparison with experiments. [9]

\section{CONCLUSIONS}

The important contributions and conclusions of this work are:

1. Key flammability properties for charring and non-charring materials can be derived by a validated methodology from measurements in existing flammability apparatuses, including the transient pyrolysis for charring materials. These properties are being used in a new Upward Fire Spread and Growth [1] simulation.

2. New similarity solutions for small- and large-scale turbulent upward flame spread have been obtained. These solutions demonstrate which parameters affect upward flame spread rates.

3. Among these parameters (e.g. ignition time, $t_{P}, x_{R}, x_{A}$ ), a very important parameter is the material flammability number MFN $=x_{R} \quad \Delta H_{c} / \Delta H_{v}$ which is related to the ratio of the flame height, $z_{f}$, to pyrolysis length, $z_{p}$. 


\section{REFERENCES}

1. Delichatsios, M.M., Mathews, M.K., Delichatsios, M.A., "Upward Fire Spread Simulation Code: Physics and Validation," FMRC J.I. OROJ2.BU, April 1990, also this Symposium.

2. Delichatsios, M.A., Panagiotou, Th., Kiley, E., "The Use of Time to Ignition Data for Characterizing the Thermal Inertia and the Minimum (Critical) Energy for Ignition or Pyrolysis," Accepted for publication in Combustion and Elame, March 1990.

3. Tewarson, A., Khan, M.M., Twenty-Second Symposium (International) on Combustion, The Combustion Institute, p 1231, Pittsburgh, PA 1989.

4. Quintiere, J. and Harkleroad, M., "New Concepts for Measuring Elame Spread Properties, NBSIR 84-2294, National Bureau of Standards, Gaithersburg, MD 1984.

5. Saito, K., Delichatsios, M.A., Venkatesh, S., Alpert, R.L., "Measurements and Evaluation of Parameters Affecting the Preheating and Pyrolysis of Non-charring Materials," Eastern Section Meeting of the Combustion Institute, December 1988.

6. Delichatsios, M.A., and Chen, Y. "Development of an Integral Model for Transient Charring Pyrolysis and Derivation of Material Flammability Properties," WPI Thesis and FMRC Report, 1991.

7. Newman, J.S., "Analysis of the FMRC Building Corner Report," FMRC J.I. OQ5E5. RC, 1989.

8. Delichatsios, M.M., Delichatsios, M.A., "Effects of Transient Pyrolysis on Wind Assisted and Upward Elame Spread," ASME/JSME Meeting, RenoBally, 1991.

9. Orloff, L., de Ris, J., and Markstein, G.H., Fifteenth Symposium (International) on Combustion, p 183, Pittsburgh, PA 1974.

10. Annamalai, K., Sibulkin, M., Combustion Science and Technology, 19, 185, 1979.

11. Delichatsios, M.A., "Burning of Upward Flame Spread in Vertical Material Surfaces: An Outline of a Comprehensive Simulation Model and Simplified Correlations," FMRC J.I. OQOJ1.BU, August 1988.

12. Hasemi, Y., Private Communication, 1991.

13. Hasemi, Y., First International Symposium on Fire Safety Science, pg. 87, NY 1986. 